\title{
The impact of surgical incision on hospital stay in patients extubated in the operating room after cardiac surgery
}

\author{
Ying Huang, MD, PhD, ${ }^{a}$ Erica D. Wittwer, MD, PhD, ${ }^{b}$ Joseph A. Dearani, MD, ${ }^{a}$ and Hartzell V. Schaff, MD $^{\mathrm{a}}$
}

\author{
From the Departments of a Cardiovascular Surgery and ${ }^{\mathrm{b}}$ Anesthesiology and Perioperative Medicine, Mayo \\ Clinic, Rochester, Minn. \\ Institutional Review Board: 18-008442 on September 26, 2018. \\ Disclosures: Authors have nothing to disclose with regard to commercial support. \\ Received for publication Nov 7, 2019; revisions received Nov 7, 2019; accepted for publication Dec 13, 2019; \\ available ahead of print Feb 19, 2020. \\ Address for reprints: Hartzell V. Schaff, MD, 200 First St SW, Rochester, MN 55905 (E-mail: schaff@ mayo.edu). \\ JTCVS Techniques 2020;1:62-4 \\ 2666-2507 \\ Copyright $\odot 2020$ The Authors. Published by Elsevier Inc. on behalf of The American Association for Thoracic \\ Surgery. This is an open access article under the CC BY-NC-ND license (http://creativecommons.org/licenses/by- \\ nc-nd/4.0/). \\ https://doi.org/10.1016/j.xjtc.2019.12.003
}

Early extubation is an important component of fast-track recovery protocols that reduce postoperative resource use, and extubation in the operating room (OR) is commonly used in patients who undergo minimally invasive cardiac surgery. ${ }^{1}$ It is generally acknowledged that minimal access incisions are associated with reduced length of intensive care unit (ICU) stay and length of stay (LOS) compared with full sternotomy. ${ }^{2}$ A systematic review and metaanalysis of mitral valve surgery reported shorter LOS with minithoracotomy. ${ }^{3}$ However, extubation status, the critical first step in an accelerated care pathway, was not addressed in these studies. To better understand the impact of surgical incision on ICU stay and LOS, we reviewed the early outcomes of fast-track patients who were extubated in the OR after cardiac surgery stratified by surgical approach.

\section{MATERIALS AND METHODS}

We identified a consecutive cohort of patients undergoing cardiac surgery who were extubated in the OR between January 1, 2015, and August 31, 2018, at the Mayo Clinic, Rochester, Minnesota. Demographics and surgery-related information were obtained from the departmental and institutional databases, and validated by review of the medical records. The study was approved by the Mayo Foundation Institutional Review Board. All patients gave informed consent for research. Patients were classified into 2 groups based on the surgical incision, full sternotomy, or less-invasive incisions, which include partial upper sternotomy and limited thoracotomies for robotic or port-access approaches. Partial sternotomy refers to upper sternotomy, and minithoracotomy refers to a right- or left-sided intercostal incision of $6.0 \mathrm{~cm}$ or less.

The primary end points were length of ICU and LOS stays, and early mortality. The secondary end points were operative time, anesthesia time, and discharge location. Descriptive statistics are reported as number (percentage) or median (interquartile range [IQR]) as appropriate. Differences between groups were assessed by chi-square analysis, Fisher exact test, or Wilcoxon rank-sum test as appropriate.

\section{RESULTS}

During the study period, 104 patients undergoing cardiac surgery were extubated in the OR. Patients' median



ICU stay and postoperative hospital stay after extubation in the OR.

CENTRAL MESSAGE

Among cardiac surgical patients who are extubated in the OR, there was little difference in ICU and hospital stay among patients with minimal access incision versus those with full sternotomy.

See Commentaries on pages 65 and 67. age was 62.5 years (IQR, 52.3-71.5 years), and 46 $(44.2 \%)$ were female. There were 44 patients $(42.3 \%)$ in the full sternotomy group and 60 patients $(57.7 \%)$ in the less-invasive incision group (13 partial median sternotomies, 40 mini or limited thoracotomies, and 7 port accesses). As shown in Table 1, the less-invasive incision group included more male patients and valve procedures, particularly single valve surgery. Other cardiac surgical procedures, not including valve surgery, and coronary bypass grafting were performed more frequently in patients with full sternotomy.

Operative and anesthesia times were similar between groups. Overall median ICU stay was 21.4 hours (IQR, 18.5-27.9 hours): 23.0 hours (IQR, 19.1-46.9 hours) for those with full sternotomy and 20.6 hours (IQR, 18.125.8 hours) for those with less-invasive incision $(P=.161)$ (Figure $1, A)$. Overall median postoperative LOS was 4.0 days (IQR, 4.0-6.0 days), 4.0 days (IQR, 3.0-5.0 days), and 5.0 days (IQR, 4.0-8.0 days), respectively $(P=.001)$ (Figure $1, B)$. No early death occurred, and $90 \%$ of patients were discharged to home. 
TABLE 1. Demographics and results of 104 patients extubated in the operating room

\begin{tabular}{|c|c|c|c|}
\hline & $\begin{array}{c}\text { Full } \\
\text { sternotomy } \\
(\mathrm{n}=\mathbf{4 4 )}\end{array}$ & $\begin{array}{l}\text { Less-invasive } \\
\text { incision } \\
(n=60)\end{array}$ & $\begin{array}{c}P \\
\text { value }\end{array}$ \\
\hline Age, y & $\begin{array}{c}61.5 \\
(45.8-71.5)\end{array}$ & $\begin{array}{c}63.5 \\
(55.3-72.3)\end{array}$ & .256 \\
\hline Female gender & $27(61.4)$ & $19(31.7)$ & .003 \\
\hline \multicolumn{4}{|l|}{ Surgical procedures } \\
\hline Valve surgery & $26(59.1)$ & $47(78.3)$ & .034 \\
\hline Single valve & $22(50.0)$ & $47(78.3)$ & .003 \\
\hline Aortic valve & 12 & 14 & \\
\hline Mitral valve & 5 & 28 & \\
\hline Tricuspid valve & 3 & 5 & \\
\hline Pulmonary valve & 2 & 0 & \\
\hline Multiple valve & $4(9.1)$ & $0(0.0)$ & .030 \\
\hline Aortic valve & 3 & 0 & \\
\hline Mitral valve & 2 & 0 & \\
\hline Tricuspid valve & 2 & 0 & \\
\hline Pulmonary valve & 1 & 0 & \\
\hline CABG & $6(13.6)$ & $2(3.3)$ & .068 \\
\hline Other cardiac surgery & $28(63.6)$ & $21(35.0)$ & .004 \\
\hline Operative time, $\min$ & $\begin{array}{c}205.0 \\
(154.0-274.0)\end{array}$ & $\begin{array}{c}202.0 \\
(179.0-239.0)\end{array}$ & .842 \\
\hline Anesthesia time, min & $\begin{array}{c}297.5 \\
(262.3-369.8)\end{array}$ & $\begin{array}{c}316.0 \\
(296.5-361.0)\end{array}$ & .081 \\
\hline \multicolumn{4}{|l|}{ Complications } \\
\hline Reintubation & $2(4.6)$ & $3(5.0)$ & 1.000 \\
\hline $\begin{array}{l}\text { Due to respiratory } \\
\text { insufficiency }\end{array}$ & 0 & 0 & \\
\hline Pneumonia & $0(0.0)$ & $0(0.0)$ & - \\
\hline Atrial fibrillation & $9(20.5)$ & $14(23.3)$ & .727 \\
\hline $\begin{array}{l}\text { Rhythm disturbance } \\
\text { requiring permanent } \\
\text { device }\end{array}$ & $2(4.6)$ & $2(3.3)$ & 1.000 \\
\hline $\begin{array}{l}\text { Renal failure requiring } \\
\text { dialysis }\end{array}$ & $1(2.3)$ & $0(0.0)$ & .423 \\
\hline Stroke & $0(0.0)$ & $0(0.0)$ & - \\
\hline TIA & $1(2.3)$ & $0(0.0)$ & .423 \\
\hline Reoperation & $2(4.6)$ & $2(3.3)$ & 1.000 \\
\hline Due to bleeding & 2 & 1 & \\
\hline Discharge to home & 40 (90.9) & $54(90.0)$ & 1.000 \\
\hline
\end{tabular}

Values are median (IQR or $\mathrm{n}(\%) . C A B G$, Coronary bypass grafting; TIA, transient ischemic attack.

\section{DISCUSSION}

Patients selected for fast-track recovery and especially those selected for extubation in the OR are low risk, and this is reflected in the low mortality in this series. Despite having somewhat more complex procedures, patients undergoing sternotomy had generally similar length of ICU stay compared with those receiving less-invasive surgical approaches. Overall postoperative hospital stay was reduced by 1 day in patients with less-invasive incisions.
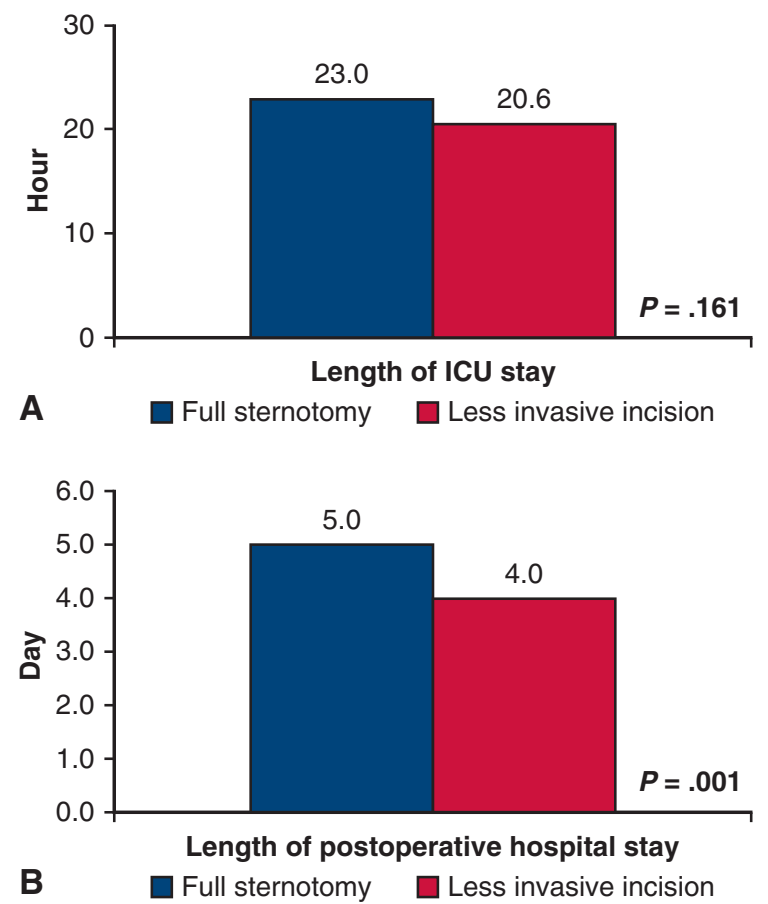

FIGURE 1. Overall median lengths of ICU stay and postoperative hospital stay in patients receiving full sternotomy (blue bar) and those receiving less-invasive incision (red bar). A, Patients receiving sternotomy had similar length of ICU stay compared with those with less-invasive incisions. B, Length of postoperative hospital stay was reduced by 1 day in patients with less-invasive incisions. ICU, Intensive care unit.

Our observation regarding the difference in postoperative LOS is similar to the result from a study comparing minimal incision with traditional sternotomy, but the prior study did not focus on extubation protocols and the potential impact of early extubation in the OR. ${ }^{2}$ A systematic review and meta-analysis of mitral valve surgery also reported decreased LOS with minithoracotomy. ${ }^{3}$ In another systematic review concerning aortic valve replacement, LOS was similar between limited and full sternotomies. ${ }^{4}$ Another study reported that both LOS and duration of ICU care were slightly reduced in patients with ministernotomy, but again, protocols for respiratory care varied..$^{5}$

Patients receiving full sternotomy had more complex procedures, whereas those with less-invasive incision required more time for surgical exposure; thus, operative times and anesthesia times were similar between the 2 groups in this study. In the systematic review and metaanalysis, minimal incision was not found to affect the procedural duration. $^{3}$

\section{CONCLUSIONS}

Our results should be considered preliminary because of the relatively small numbers of subjects in each group in this retrospective study and the uncontrolled selection of patients. Nevertheless, our data emphasize the importance of 
extubation protocols when comparing early outcomes and resource use of minimally invasive procedures with those performed through full sternotomy.

\section{References}

1. Badhwar V, Esper S, Brooks M, Mulukutla S, Hardison R, Mallios D, et al. Extubating in the operating room after adult cardiac surgery safely improves outcomes and lowers costs. J Thorac Cardiovasc Surg. 2014;148:3101-9.e1.

2. Atluri P, Stetson RL, Hung G, Gaffey AC, Szeto WY, Acker MA, et al. Minimally invasive mitral valve surgery is associated with equivalent cost and shorter hospital stay when compared with traditional sternotomy. J Thorac Cardiovasc Surg. 2016; 151:385-8.

3. Al Otaibi A, Gupta S, Belley-Cote EP, Alsagheir A, Spence J, Parry D, et al. Mini-thoracotomy vs. conventional sternotomy mitral valve surgery: a systematic review and meta-analysis. J Cardiovasc Surg (Torino). 2017;58: 489-96.

4. Kirmani BH, Jones SG, Malaisrie SC, Chung DA, Williams RJ. Limited versus full sternotomy for aortic valve replacement. Cochrane Database Syst Rev. 2017;4: CD011793.

5. Brown ML, McKellar SH, Sundt TM, Schaff HV. Ministernotomy versus conventional sternotomy for aortic valve replacement: a systematic review and meta-analysis. J Thorac Cardiovasc Surg. 2009;137:670-9.e5. 